\title{
Ruedas de coplas y mundos de experiencia en la quebrada y los valles orientales de Jujuy
}

\section{Wheel of coplas and worlds of experience in the gorge and the eastern valleys of Jujuy}

\author{
Radek Sánchez Patzy ${ }^{1}$ (D) https://orcid.org/0000-0002-6612-9451
}

${ }^{1}$ Instituto Interdisciplinario Tilcara, Facultad de Filosofía y Letras, Universidad de Buenos Aires, Tilcara, ARGENTINA. Email: radek.sanchez@gmail.com

\author{
Huella, huellita, \\ huella sin cesar, \\ ábrase esta rueda \\ y vuélvase a cerrar ${ }^{1}$
}

\section{Resumen}

Las ruedas de coplas en la quebrada y los valles orientales de altura de Jujuy son un tipo de canto acompañado por cajas, propio de la época estival. Se inician con la celebración a los difuntos y continúan activas hasta el entierro del carnaval. Con este artículo quiero ensayar algunas reflexiones sobre la rueda en tanto actividad creativa y social, que "da ánimos" o "que aleja la tristeza". A partir de mi experiencia de campo, de la narrativa de copleras y copleros y del análisis de coplas vernáculas, analizaré las características del ingreso a la rueda, que implican, según la consideración general, un quiebre con el sentido común de la vida cotidiana. En esas circunstancias, los sentidos pueden responder de maneras imprevisibles, lo que supone la búsqueda de nuevos conocimientos y recursos que permitan a los y las participantes otorgar sentido a ese nuevo orden de cosas; efímero, pero sumamente deseado. En estos casos, a través de los climas sonoros y la ingesta de alcohol, en los que la singularidad del cuerpo se confunde con la organicidad de la rueda, pueden producirse discursos disidentes y una pérdida del sentido del tiempo, mientras se insiste en la búsqueda por generar alegría y belleza.

Palabras clave: Rueda de coplas, experiencias corporales, quebrada de Humahuaca, valles orientales de altura, copleras/copleros.

1 Copla no octosílaba, corriente en la quebrada de Humahuaca y los valles orientales de Jujuy. Se entona al interior de la rueda invitando muchas veces a cantar con más energía, operando como un empuje colectivo hacia el festejo y la algarabia, como me mencionó un coplero de Molulo en marzo de 2005. 


\begin{abstract}
The wheels of coplas in the gorge and the eastern high valleys of Jujuy are a type of song accompanied by cajas (drums), typical of the summer season. They begin with a celebration for the deceased and continue active until the funeral of the carnival. With this article I want to offer some reflections on the wheel as a creative and social activity, that "encourages" or "that drives away sadness". From my field experience, the narratives of copleras and copleros and the analysis of vernacular coplas, I will analyze the characteristics of entry into the wheel, which imply, according to general consideration, a break with the common sense of everyday life. In these circumstances, the senses can respond in unpredictable ways, which means the search for new knowledge and resources that allow participants to give meaning to this new order of things, ephemeral, but highly desired. In these cases, through sonorous climates and alcohol intake, where the singularity of the body is confused with the organic nature of the wheel, dissident discourses and a loss of the sense of time can occur, while still insisting on the search for generating joy and beauty.
\end{abstract}

Keywords: wheel of coplas, body experiences, quebrada de Humahuaca, high eastern valleys, copleras/copleros.

Recibido: 20 mayo 2020. Aceptado: 19 agosto 2020 


\section{Ábrase esta rueda...}

Dentro de la heterogeneidad sonora y musical de la quebrada de Humahuaca y los valles orientales de altura de Jujuy intentaré detenerme en este trabajo, en un tiempo y un espacio precisos, aquel en el que reina la rueda de coplas estival, período festivo que se inicia después de la celebración de "Todos Santos" a principios de noviembre y culmina con el entierro del carnaval.

El canto de coplas del Noroeste Argentino (NOA) ha sido ampliamente estudiado tanto desde la musicología (Aretz, 1952; Vega, 1965; Cámara de Landa, 1994, 2006; Valladares, 2000, entre otros) como desde diversos estudios literarios y folclóricos (Carrizo, 1935; Taboada, 1996; Mirande, 2005, 2010, 2018; Zapana, 2011) o desde la antropología (Mennelli, 2007, 2010a y b), entre otros. Es el resultado de la imbricación de tradiciones hispánicas y locales. Se compone de cuatro versos octosílabos con rima asonante en el segundo y el cuarto verso. Las tonadas, que implican sutiles variaciones melódicas en el canto de coplas, hacen más complejo el fenómeno, pues cada localidad tiene la suya propia, a la que se deposita un inmenso valor afectivo. De esta manera, cada coplero o coplera ${ }^{2}$ tiene su propia tonada y será con ella que interprete sus coplas. Respecto a las características musicales de la copla, esta se define por el uso constante de tres sonidos, que coinciden casi siempre con el acorde perfecto mayor, con algunas notas de paso.

He tenido la oportunidad de participar muchas veces en ruedas, básicamente como escuchador, aunque alguna vez, un poco motivado por la copla que dice: "Meta y nueva meta y mueva/ como quirquincho en la cueva/ si no sabes cantar coplas/ siquiera la boca mueva", me he animado a formar parte del coro que responde los versos que se cantan. Al ingresar a la rueda, una condición para poder quedarse es no desairar al anfitrión, aceptando todas las bebidas que te convidan, desde un trago a la puerta de la casa, o del corral donde se realiza una señalada, pasando por el vino y la chicha de maíz entre una gama amplia de licores. En las señaladas de los rebaños, las marcadas del ganado ${ }^{3}$ y en los festejos propios del carnaval, algunos copleros, provistos de sendos manojos de coca, empiezan a tańer las cajas y a entonar los primeros versos. Y la copla se mantendrá así por horas: "dando vuelta, dando vuelta, como piedra en el molino", en una melodía monótona ritmada solo por las cajas que marcan la cabeza del compás, con estruendo. En estas circunstancias, he podido experimentar que los sentidos empiezan a responder de otro modo y el mundo se presenta distinto, alejado del sentido común de la vida cotidiana. Intentaré aproximarme a esta primera percepción, tratando de ensayar algunas ideas a partir de mi experiencia de campo, de las narraciones de copleras y copleros y de lo que creo entender que me dicen sus coplas.

En este escrito pondré el acento en mi experiencia de campo, en entrevistas y en algunas coplas vernáculas, que provienen en todos los casos de la quebrada y los valles orientales de altura de Jujuy, ensayando una reflexión sobre las percepciones y lo cognitivo dentro de la rueda de coplas que "revitaliza", "que da ánimos" o "que aleja la tristeza", como he escuchado decir a

2 He optado por utilizar el lenguaje binario ("los" y "las") para los sustantivos "copleros" y "copleras", puesto que son las categorías nativas que se emplean al interior y al exterior de la rueda de coplas. En algunas entrevistas, aparece el masculino "coplero" para contener al femenino "coplera", salvo que indique lo contrario.

3 La señalada consiste en una señal particular en las orejas de los animales, mediante un tajo que se les realiza. En la marcada se pone una marca distintiva en el muslo del animal. Ambas prácticas permiten distinguir a los animales en caso de pérdida. En todos los casos, los animales se floran, es decir, se les coloca un chimpo en sus orejas o lomos, pedacito de lana de colores sin hilar. 
muchos avezados copleros y copleras de la región. En suma, las situaciones vividas que referiré son elementos narrativos que la "sensibilidad fenomenológica puede ayudar a describir" (Sanjinés, 1996, p. 15), enfatizando la interpretación corporal y verbal de la experiencia coplera, entendido como un conjunto de acciones que pueden representar o reflejar un sistema social o una configuración cultural específica.

El dualismo cartesiano no repara en el hecho de que el cuerpo humano no es solo sostén, sino agente activo de la subjetividad. Reconocer este hecho es uno de los méritos de la investigación fenomenológica de Maurice Merleau-Ponty (1985 [1945], quien inaugura el estudio de la sociología del cuerpo. En este trabajo la aproximación tendrá que ver con un tipo específico de cuerpo, un cuerpo que canta y que, por supuesto, escucha, y que también baila ("quebrantea", al decir de un coplero amigo), transitando quiebres con el sentido común y la vida cotidiana, inducidos no solo por la ingesta de alcohol sino, probablemente, por este canto repetitivo y creativo, que constituyen las coplas. De ahí que resultará un punto central en esta exposición aprovechar algunos argumentos sobre ciertos quiebres con el sentido común y la vida cotidiana, que el antropólogo norteamericano Byron Good (1994), retomando a Alfred Schutz (2008 [1962]), ha abordado en función de la experiencia de la enfermedad. En este caso, me referiré a estados de explosión de percepciones -fiesta, éxtasis, por decirlo con las palabras de otro coplero-, entendiendo la rueda de coplas no solo como objeto de cognición y conocimiento, sino, al mismo tiempo, como un complejo agente de experiencias, en las que ciertas dimensiones se escapan o se suspenden, pero otras permiten visibilizar discursos disidentes que renegocian los roles sociales e imaginan alternativas de ordenamiento social, al menos hasta el momento en que la rueda se vuelva a cerrar.

Con esta elección teórica, específica para el análisis puntual, no quiero descuidar que las ruedas de coplas en Jujuy están insertas en un contexto de sentido mucho más amplio y complejo, y que pueden analizarse desde otras perspectivas teóricas. Las características para pensar los quiebres con el sentido común y la vida cotidiana propuestas por Schutz pueden ser útiles como modelo, pero nunca serán precisas completamente. Las he aprovechado como una estrategia analítica que me permita esbozar algunas respuestas a mis preguntas de investigación. Así pues, no pretendo realizar una exhaustiva revisión sobre la cuestión de las experiencias de mundo relacionadas a un fenómeno propio de la cultura popular jujeńa, tan solo busco iniciar una reflexión sobre algunos elementos relevantes que la conforman.

\section{Algunos apuntes sobre la fenomenología de la percepción}

Para entrar en tema, la percepción según Merleau-Ponty (1985 [1945]) es una experiencia corporal que adquiere significado a través de los sentidos. El autor propone romper con la escisión entre la mente y el cuerpo, como distingue la perspectiva cartesiana. Según esta, mientras el cuerpo se extiende en el espacio, es divisible y obedece a leyes físicas; la mente, por el contrario, es una sustancia pensante, indivisible, y ajena a cualquier tipo de determinismo físico. Si el cuerpo es un objeto material, la mente es un sujeto pensante (Le Breton, 1995; Sanjinés, 1996). El cuerpo humano es en realidad un todo indivisible que percibe: "[...] por ello, el cuerpo es sensible y sensitivo: ve y es visto; oye y es oído; toca y es tocado. Lo sensible y lo sensitivo son, entonces, aspectos reversibles del cuerpo humano que le permiten a éste ser observador visible, tocador tangible y oidor audible" (Sanjinés, 1996, p. 17). Al plantear estas ideas, Merleau-Ponty redefine el campo de la percepción: 
No se trata ya de juntar sustancias diferentes (cuerpo/mente, sujeto/mundo) o reconciliar dominios distintos (lo interno y lo externo), sino repensarlos como aspectos relacionados, imbricados y reversibles de una misma textura. De este modo, el fenomenólogo francés se refiere tanto a la "carne del cuerpo" como a la "carne del mundo" para expresar esta reversibilidad de lo sensible y lo sensitivo, y la imbricación del observador con lo observado. El cuerpo humano tiene, pues, su lado objeto, es decir, su lado sensible que puede ser visto y tocado, pero también su lado sujeto, que ve y toca (Sanjinés, 1996, p. 17).

Puedo agregar a ello aquel lado sensible del sujeto que puede ser escuchado y que escucha, en esta reversibilidad de lo sensible y lo sensitivo, retomando la distinción que el músico canadiense Murray Schafer hace entre campos sonoros y paisajes sonoros. En los primeros se destacan la acción de producción/emisión de sonoridades, en cambio los segundos se refieren a su apropiación/recepción que, de esta forma, parecen capaces de reterritorializar y volver específica la acústica indiferenciada del campo sonoro (Fortuna, 2009, pp. 44-45). De este modo, es central la apropiación/recepción activa de quien escucha, en oposición a los planteos de Georg Simmel. Para este sociólogo, el dinamismo de lo visual y del mirar arrastran consigo la marginalidad del oído:

El sentido auditivo es, para Simmel, un sentido pasivo, despojado de autonomía propia, lo que contrasta de forma evidente con la vista. En la relación cara a cara, esta última siempre implica comunicación, por lo que el autor del Ensayo sobre la Sociología de los Sentidos reconoce que el mirar "no puede dar sin recibir", mientras el oído está destinado a recibir sin (poder) dar (Fortuna, 2009, p. 42).

Egoísmo y pasividad serían las características del sentido humano del oído, condenado a "recibir" sin criterio todos los estímulos que se le ofrecen, sin poder ser, como sucede con el mirar, deliberadamente interrumpido o desviado de todo cuanto no nos interesa o despreciamos (Fortuna, 2009, pp. 43 y 54). Esta idea está bien ilustrada por el ensayista y poeta francés Pascal Quignard (2004), cuando afirma: “Ocurre que las orejas no tienen párpados”. Pero el oído nunca fue el sentido pasivo que sostuvo Simmel. No solo el uso de los dispositivos musicales en boga demuestra la direccionalidad auditiva que la tecnología nos permite, esta capacidad ya está presente en nuestros oídos, por más que nuestras orejas no tengan párpados, sabiendo direccionar su atención a determinadas fuentes sonoras, ya sea en una charla cruzada entre personas sentadas alrededor de una mesa o focalizándose en un sonido especial en medio de la bruma sonora callejera.

Pensada así la apropiación activa de lo sonoro, la reversibilidad de lo sensible y lo sensitivo, sorprende la fuerza con la que las tierras altas de Jujuy suena y es apropiada y recibida por sus habitantes. Y si bien el paisaje sonoro local tiene mucho de patrimonialista (representado en los repertorios de anatas, erkenchos, cornetas, sikus y el universo de la copla, aunque también en las bombas de estruendo, las campanas de las iglesias y la voz cantante de la matraca), según la reflexión de Fortuna, los sonidos de lo moderno, de lo mixturado, suenan con una vitalidad a toda prueba, denotando lo alejada que se encuentra esta realidad de la comunidad folk, ahistórica, arrelacional y romántica prevaleciente en muchos estudios sobre el folclore en la región. Antes bien, en las prácticas sonoras mencionadas es posible ingresar a la manera de entender el mundo de las poblaciones locales, su relación con las fuerzas invisibles, sus gustos, su sentido del humor, sus narrativas de identidad y sus posicionamientos políticos. 
Otro aspecto de la teoría de la percepción merleau-pontiana se basa en el comportamiento activo de los cuerpos. Mirar, oír, tocar, son hábitos culturales no pasivos. Para Merleau-Ponty, los cuerpos sensibles no solo reciben mensajes que interrogan al mundo de manera activa, emitiéndolos. El sujeto es inseparable del mundo, pues siempre es un ser-en-el-mundo. Por ese motivo, la función primaria de la percepción es la acción, el compromiso práctico. Este aspecto es fundamental "[...] porque sugiere que la percepción está constituida a través de la relación activa del cuerpo con el mundo" (Sanjinés, 1996, pp. 17-18). Para Citro (2009), se trata de una rigurosa bilateralidad: "[...] no puede constituirse el mundo como mundo ni el yo como yo si no es en su relación. De este modo, la fenomenología introduce la cuestión del otro y de la construcción intersubjetiva del sentido del mundo, diferenciándose de los planteos racionalistas clásicos que centraban este problema exclusivamente en el individuo y su razón” (Citro, 2009, pp. 46-47). Aun más, para Merleau-Ponty solamente los cuerpos activos encarnan y dan sentido a las ideas.

La cuestión del otro ha sido abordada de manera interesante por Carlos Cullen (1978), quien propone como punto de partida de una fenomenología el nosotros (que sería el pueblo), en lugar del yo (que es la conciencia, según Hegel). A esta inquietud, Cullen suma la de desarrollar el concepto de "sabiduría popular", como una alternativa a los diferentes proyectos de sabidurías: "Al yo pienso, que en definitiva determina la fenomenología como ciencia de la experiencia de la conciencia, le oponemos el nosotros estamos, como sabiduría de la experiencia de los pueblos [...]. Pueblo es, pues, la experiencia del nosotros estamos" (Cullen, 1978, p. 13, los destacados son míos). Una sabiduría popular que se expresa en cantos, cuentos, leyendas, y también, agrego yo, coplas.

Esta comprensión práctica o existencial es la que quiero cotejar con mi experiencia en el ingreso a la rueda de coplas, donde los cuerpos vivientes no son cosas inertes, sino formas de "estar-en-el-mundo" en el sentido de habitarlo, interpretarlo y transformarlo. En las coplas se revelarían maneras de entender el mundo, de ese nosotros estamos, de quienes las echan al aire, constituyéndose en un instrumento de comunicación de esa sabiduría popular, y como quiero proponer, en un agente múltiple de experiencias.

\section{Las festividades estivales, el carnaval y las ruedas de coplas en contexto}

Cada región en los Andes meridionales tiene un tipo particular de calendario agrario, ritual y organológico; no obstante, pareciera constituirse una suerte de "paradigma sonoro-instrumental andino" conceptualmente constatable en las tierras altas de Jujuy. El verano tiene relación directa con las divinidades de la tierra, las fuerzas vivas del paisaje vinculadas a la fertilidad agropecuaria e incluso a la creación musical. Seres sobrenaturales como San Carnaval y el Pujllay pertenecen a esta época del año, los que junto con la Pachamama mantienen una relación con los seres humanos mediada por un hambre que obliga a estos a ofrecer libaciones de comida y bebida (pagarles, se dice comúnmente) a cambio de abundancia productiva y alegría en las fiestas, mediante la apertura de una boca o mojón, ara ritual señalada por un montículo de piedras amontonadas que actúan como conexión con el "mundo de abajo" donde habitan estos seres vinculados a la imagen del "diablo del carnaval".

Según los testimonios que recogí en los valles orientales de altura, además de coplas, San Carnaval habita lugares solitarios, próximos a peñas altas, desde donde brotan vertientes de agua o manantiales. Estos son espacios de la Salamanca, espacios que se piensan como un pueblo 
difuso, espectral, por detrás de una puerta, donde se festeja con desenfreno. Se trata de un espacio asociado con los seres del inframundo y al poder genésico que se les atribuye.

En la quebrada de Humahuaca, las copleras y copleros, como ocurre con todas las agrupaciones carnavaleras, desentierran el carnaval y lo vuelven a enterrar nueve días después, aunque hay quienes entierran el Miércoles de Ceniza, ateniéndose al calendario católico más tradicional. Tanto el desentierro como el entierro implican una serie de acciones en los mojones, pozos o bocas de la Pachamama cuya presencia se indica con un montículo de piedras y que por lo general se encuentran en los cerros o cerca de los ríos, por fuera del espacio de la ciudad colonial (Costa y Karasik, 2010 [1996]) o, como ha observado Mennelli (2007) para el caso humahuaqueño, cerca de antigales, lo que refuerza la expresión de un espacio sagrado relacionado con los antepasados o los "antiguos"; es decir, como espacios liminales y simbólicamente significativos. En todos los casos, la comunicación con las entidades del inframundo se materializa a través de fluidos vertidos en el acto de challar (asperjar con alcohol y otras bebidas en la "boca de la Pachamama"), libaciones que son imprescindibles para saciar la sed de la tierra. En la ceremonia están siempre presentes las hojas de coca que se ofrendan, consagradas junto con las sahumadas de q’oa. Líquidos y humo, como han descripto Bugallo y Vilca (2001) fluyen por espacios y aberturas relacionando a los seres en distintas dimensiones.

Otro momento central en las celebraciones de fertilidad y abundancia del verano se produce durante las marcadas del ganado y seńaladas de los rebańos (Sánchez Patzy, 2006). Se realizan entre noviembre y marzo, época en la que los animales tienen tres o cuatro meses. A esa edad es necesario identificarlos, para poder recuperarlos en caso de extravío, mediante una señal, que consiste en un pequeño corte en las orejas que se floran con pedacitos teñidos de vellón sin hilar, lo que se considera atraerá la buena suerte y la procreación de la tropa (Bugallo, 2010). $\mathrm{Al}$ año siguiente, los vacunos serán marcados, con un hierro candente, para identificarlos con el resto de la tropa y con sus dueños.

En todos los casos, se empieza al mediodía y, según la cantidad de animales, se puede seguir con la tarea hasta el anochecer. De esta manera, los miembros de la comunidad reafirman los lazos de parentesco y de reciprocidad. Cuando la faena ha terminado, se dan tres vueltas dentro del corral cantando coplas en honor a los animales, inmediatamente después se los "despacha" en dirección del "sol de mañana". En ese momento los dueños de la hacienda o el rebaño convidan con bebidas y comidas en su casa, coronándose con ruedas de copleras y copleros que festejan durante horas, incluso hasta la madrugada del día siguiente.

El sonido y el movimiento permean la rueda en un abanico de posibilidades de participación que van desde la escucha serena al movimiento corporal constante y acompasado; del canto responsorial a la voz cantante; del toque estruendoso de las cajas y los erkenchos ${ }^{4}$ al concurso de los fuegos de artificio, que pueden devenir en climas sonoros empleados para marcar transiciones. Los cuerpos siguen el pulso de las cajas balanceándose lentamente, con ligeros quiebres de cadera al proponer una nueva copla ("quebranteando"). Esta cadencia hará que los cuerpos inevitablemente se muevan en una única dirección, siempre en sentido contrario a las manecillas del reloj.

4 El erkencho o erke es un tipo de clarinete idioglótico formado por un pabellón de asta de vacuno vaciada. El extremo más angosto del asta se agujerea para introducir una boquilla o pajuela muy delgada hecha de cańa con un extremo cerrado. A esta pajuela se le practica una incisión longitudinal casi hasta la mitad, que da por resultado una fina lámina que actúa como lengüeta batiente. Los erkencheros se sitúan siempre por fuera de la rueda, tańendo la caja con la otra mano. 
En la rueda de coplas el oído debe aguzarse enormemente, como característica básica de la reversibilidad de lo sensible y lo sensitivo. Ante una copla con una temática dada, el intérprete responderá con otra copla relacionada. El carácter musical y las temáticas poéticas cambian según la estación de que se trate. A diferencia de la copla de la época seca del año, que se canta a solo, con temáticas introspectivas, la copla estival se define, sobre todo, por su algarabía y por su carácter colectivo. Existen diversas formaciones de intercambio de coplas; la más común, el canto colectivo (en ruedas de coplas), en la que un coplero o coplera lanza los dos primeros versos que serán repetidos por el coro. Luego cantará los dos versos faltantes que nuevamente se repetirán.

Otra de las modalidades existentes es el contrapunto, en el que la capacidad de escucha y respuesta es aún más aguda. Consiste en un desafío entre al menos dos personas, generalmente hombre y mujer, cuyas repeticiones pueden ser acompańadas por los demás copleros, que generan gran expectativa entre los participantes de la rueda. Se cińen a un orden medianamente establecido: primero se entonan las coplas de requiebro o cortejo amoroso y de chanzas pícaras sobre el aspecto físico o el género opuesto, que exigen, por parte de los cantores, conocimiento del repertorio común, la semiimprovisación verbal y el seguimiento lúcido de los versos del otro cantor, pues se debe tener lista una respuesta ingeniosa para que el juego continúe. Posteriormente las coplas empiezan a ser más punzantes y suelen aparecer algunas con contenido sexual.

\section{"Cuando llega el carnaval/ no almorzo ni ceno nada/ me mantengo con las coplas/ me duermo con la tonada”: La experiencia del mundo vital de copleros y copleras en la rueda}

Schutz (2008 [1962]) distingue la actitud natural del mundo cotidiano de otras formas básicas de realidad: los sueños, las fantasías, el mundo del arte, el de la ciencia, o el mundo de la experiencia religiosa, señalando en cada una de ellas características específicas, es decir, con formas propias de organizar la experiencia y modos de actuar que el sociólogo trató de identificar, mostrando que la realidad de sentido común se caracteriza por ser un mundo intersubjetivo: “[e]sto implica, por un lado, que este mundo no es mío privado sino común a todos nosotros; y por el otro, que en él existen semejantes con quienes me vinculan muchas relaciones sociales. No solo actúo sobre cosas inanimadas, sino también sobre mis semejantes; ellos me inducen a actuar y yo los induzco a reaccionar" (Schutz, 2008 [1962], p. 206). Schutz, en sus escritos finales, no concibe negativamente al sentido común, como carente de la racionalidad del sentido científico, al contrario: ambos implican un conjunto de abstracciones, generalizaciones y formalizaciones que la ciencia no hará más que continuar (Schutz, 2008 [1962]; Belvedere, 2013). En tanto constructo, el pensamiento de sentido común nos proporciona en la vida cotidiana un conocimiento de las dimensiones del mundo social que no es fragmentario, si bien se encuentra restringido a determinados sectores del mismo y a menudo puede contener inconsistencias (Belvedere, 2013, p. 35).

Para poder dar cuenta del quiebre con el sentido común y la vida cotidiana que sugiero inherente a la rueda de coplas, se precisa de una estrategia descriptiva. En este caso, opto por la reflexión sobre los artefactos culturales de narración de los que se valen los copleros y las copleras para plasmar sus experiencias, en el delicado intervalo que va entre que se "abre la rueda y se vuelve a cerrar" y, por supuesto, las narraciones tomadas de diversas coplas. Al ser el mundo solo comprensible en la medida en que lo relatamos, la producción sonora, y las entrevistas abiertas o semiestructuradas nos proveen de relatos o narrativas para ubicarnos dentro de ellos. Como 
es sabido, la narrativa se refiere a la capacidad de los seres humanos de narrar y contar historias a los demás, las que dependen de las situaciones, audiencias, perspectivas individuales y relaciones de poder que se establezcan. De esta manera, las múltiples narrativas de los eventos y de los procesos identitarios constituyen, a su vez, sitios potenciales de competencia y conflicto, aunque también lo son de consenso y cooperación (Vila, 1995).

Ahora bien, hay experiencias que irrumpen como situaciones que cuestionan lo cotidiano y el sentido común, como ocurre con la enfermedad, como ha estudiado Good (1994). Esto también puede ser válido para explicar los "saltos" o "conmociones" tal como los entiende Schutz (2008 [1962]), es decir, aquellas modificaciones radicales en la tensión de nuestra conciencia, en situaciones como las que se viven al interior de la rueda de coplas. En estas experiencias, la ruptura de lo cotidiano se presenta como una situación especial donde los sentidos y el cuerpo todo responden de maneras imprevisibles, lo que se dice extra-ordinarias. Esto supone una movilización por parte de los individuos en busca de nuevos conocimientos y recursos que les permitan otorgar sentido, explicar y dar respuesta al nuevo orden de cosas.

Estas características de la realidad de sentido común señaladas por Schutz, y empleadas por Good para indagar el mundo de la enfermedad crónica, bien pueden ser empleadas para examinar cómo los sentidos alterados vinculados a la rueda de copleros y copleras subvierten, a veces módicamente, a veces intensamente, ese mundo cotidiano del sentido común mediante "conmociones específicas", en la transición de un ámbito de experiencia a otro. Resulta necesario, en este punto, retomar el concepto fenomenológico de epojé, según lo entiende Schutz, que tiene que ver con la suspensión de nuestra creencia en la realidad del mundo, o como recurso para suspender la duda:

Por ello, al estilo cognoscitivo peculiar de cada uno de estos diferentes ámbitos de sentido corresponde una tensión específica de la conciencia y, por consiguiente, una epojé específica, una forma predominante de espontaneidad, una forma específica de experiencia del sí-mismo, una forma específica de socialidad y una perspectiva temporal específica (Schutz, 2008 [1962], p. 217).

A continuación iré desgranando dichas características de la realidad del sentido común -siendo recurrente que aparezcan las experiencias de la conciencia de copleros y copleras y sus narrativas de identidad, por su característica transversal- para reflexionar sobre las particularidades de lo que ocurre dentro de la rueda de coplas en relación a cada una de ellas. ${ }^{5}$

\section{Cuando "el diablo mete su cola": la experiencia del desconocerse}

Según Schutz (2008 [1962], p. 216; Good, 1994, p. 229) el yo es experimentado como el autor de sus actividades; como sí-mismo total e indivisible, basado en el yo puedo planteado por Merleau-Ponty, a través de nuestros cuerpos. Esta característica de lo indivisible se desdobla, descontrola y desconoce en la rueda. Sin embargo, por lo menos al llegar a ella, parece mantenerse la conciencia de la autoría de nuestros actos:

Aqui estoy porque'i venido

Porque'i venido aqui estoy,

5 A los fines expositivos, he modificado el orden original en que Schutz consigna las características básicas del mundo del ejecutar. 
si no le gusta mi modo

como'i venido me voy.

O bien,

Cuando me paro me paro

cuando me agacho me agacho,

cuando me paro en la rueda

soy más duro que un quebracho.

(Ambas coplas fueron registradas en Molulo, enero de 2006. Recopilación propia).

Uno va a la copla conscientemente. La alegría debe invadirnos, para olvidarnos de la tristeza:

Asi soy cuando yo quiero,
cuando yo quiero asi soy.
De las penas me deshago,
y a la diversión mi voy.
(Copla escuchada en San Francisco, abril de 2015).

Sin embargo, existe la posibilidad, para algunos, de que el cuerpo no actúe con absoluta soberanía, por influjo de una fuerza invisible que lo compele, como me comenta Quintino Arias, coplero de Santa Bárbara (en los valles orientales):

Claro, como es una alegría mayor y que siempre está la bebida de por medio, el alcohol. La gente normal lo festeja como corresponde, sin salirse del contexto, digamos. Pero hay mucha gente que es débil, que se enloquece de la misma alegria y a veces pierde el control [...], no sabemos cómo ni por qué; es por la misma alegría que les invade, que es mucho que no aguanta, no soporta y, bueno, va a terminar con alguna consecuencia, que a veces puede ser lamentable. De ahi ya sale el dicho que "el diablo metió la cola", que a veces también en los matrimonios, a veces se cambian el matrimonio, a veces, ya sea el hombre o la mujer parece que se enamora más, se llena de amor, se pierde, ya no le importa su pareja y se van con alguien que le gustó en el momento y en donde se dice, se usa siempre: "el diablo metió la cola", es como la fuerza negativa que le hace hacer las cosas que no corresponde [...]. Te sucede porque la alegría te invade demasiado y no lo controlás y, bueno, llega a alguna consecuencia (Quintino Arias, com. pers., abril de 2005).

Al meter el diablo su cola, los copleros y copleras harían cosas por fuera de su control o voluntad. Puedo entrever que la narración y la narratividad -como instrumentos que median, arbitran o resuelven en el discurso las conflictivas afirmaciones de lo real y lo imaginario- muestran estrategias narrativas que son la fuente de juicios contrapuestos. Por un lado, puede producirse un tipo de escisión del sujeto; por otro, pueden emerger, a posteriori, juicios de tipo moral. A continuación reflexionaré sobre ambas estrategias.

En los días del carnaval en la quebrada de Humahuaca, es común escuchar, en circunstancias en las que alguien ha bebido mucho y ha cometido algún tipo de "exceso", que dicha persona "se ha desconocido". En efecto, he escuchado esta expresión aplicada a borrachos o borrachas que han provocado algún tipo de incidente o gresca de cierta consideración. En una ocasión, oí 
decir que dos varones "se habían desconocido", cuando mi entrevistado recordaba que, al calor de la fiesta y la bebida, habían tenido algún tipo de acto homoerótico u homosexual.

En estos casos los cuerpos seguirían siendo los autores de sus actos, continuando con MerleauPonty, pero ya no como sujetos creativos totales, desconociéndose. ¿Qué nos dice la narrativa de los copleros y copleras al respecto? Las coplas se cantan en una primera persona omnipresente, no obstante, in situ, como la alegría invade demasiado, puede producirse esta suerte de desdoblamiento de esa autoría del yo, cercana a la expresión antes citada. Muy en relación a la imagen del intérprete de coplas que hace cosas por fuera de la realidad del mundo cotidiano, puede darse una disociación narrativa en la construcción sintáctica autorreferencial de algunas coplas. Mirande apunta una cuarteta interpretada por una coplera, para analizar un tipo de contradiscurso femenino, dentro de lo que la autora denomina "relatos de la mujer cantora" (Mirande, 2018, p. 23):

\section{Alegre m'estoy cantando, nada me estoy acordando; los quehaceres de mi casa, todos m'estoy olvidando (Mirande, 2010, p. 165).}

La enunciación "Me estoy cantando/ me estoy acordando" da cuenta, para Mirande, "de la emergencia de un sujeto disociado entre una voz y una escucha, que canta para sí pero que a la vez se vuelve él mismo parte del canto" (Mirande, 2010, p. 165). Para la autora, esa disociación hace emerger a un sujeto "otro" con voz propia, cuestión bien expresada en los dos últimos versos de la cuarteta: "los quehaceres de mi casa/ todos mestoy olvidando", recurriendo incluso a la tercera persona. En esa misma copla, además, es notable cómo la vida cotidiana sigue sucediendo mientras el yo de la coplera se encuentra en la rueda, como si se pudiera habitar en dos dimensiones.

Puede surgir, entonces, una identidad nueva -o tal vez interior-, simbolizada en la "máscara" de talco y harina con la que se pintan los rostros, la serpentina y el papel picado que cubren todo el cuello y la cabeza. Las coplas, y de manera notable las coplas cantadas por mujeres, pueden constituirse en el vehículo de cuestionamiento de los roles de género, la habilitación a un discurso que subvierte o pone en entredicho momentáneamente el orden patriarcal instituido.

Así pues, el yo, experimentado como autor de sus actos de manera indivisible, puede ponerse en entredicho, por lo menos momentáneamente, al ingresar a la rueda. Tal vez es posible plantear la hipótesis de esta disociación del yo en el caso que presento, apelando a etnografías sobre el mundo andino: como dos personas que son al mismo tiempo la persona del sujeto que se emborracha. Respecto a esta escisión del sujeto que implica que uno pueda desconocerse a sí mismo como parte del acto de embriagarse, Robert Randall (1993) ha destacado la distinción que existe entre ukhurunanchis y hawarunanchis, términos quechuas que quieren decir 'nuestra persona de adentro' y 'nuestra persona de afuera', respectivamente. Anota, citando a Carpenter, que en el quichua de Ecuador se dice que el individuo borracho "está en otra cabeza (shuk umapi tiyajun)", y por eso su persona exterior no es responsable por las acciones de su persona borracha (o interior). Así mismo, en Ollantaytambo es común saludar a un borracho con la frase "personaykirì" (¿Y cómo está tu persona...?) (Randall, 1993, p. 71). Todo lo cual permite "[...] entender por qué la borrachera puede ser subversiva, ya que la persona que se emborracha es la "otra persona" de adentro - un salvaje, no-civilizado identificado con el mundo de la noche y del pasado" (Randall, 1993, p. 72). 
Para el caso mencionado más arriba, los dos borrachos que se habian desconocido, movidos por su "otra persona" u "otra cabeza" interior - ¿ese diablo que mete su cola no es esa "otra persona" o "cabeza interior"?-, se permitían de esta manera subvertir ciertas estructuras, de manera momentánea, apelando a la licencia que habilita el carnaval. La conciencia subjetiva se manifiesta entre coplas, como esta que menciona a la "cabeza interior":

\author{
Caramba que me'i machado \\ tomando un vaso'i cerveza \\ he perdido mi caballo \\ causa mi mala cabeza \\ (Copla escuchada en Abra Potrero, Molulo, 2015)
}

Por otra parte, según la narrativa expresada por copleros y copleras, puede darse a posteriori una base para la emergencia de juicios moralizadores: aparece en el relato de Arias una idea moral sobre un límite que no se debería franquear, aun en la experiencia extrema y sumamente deseada de macharse $e^{6}$ festejar cantando: "Te sucede porque la alegría te invade demasiado y no lo controlás", "hay gente que es débil". Incluso en esas circunstancias que pueden constituirse en una ruptura del orden moral, en la narrativa aparecen invocados juicios que hablan sobre la necesidad de un "balance".

\title{
2. "La que toma es la rueda": ánimo, organicidad de la rueda y nosotros in- tersubjetivo
}

Para Schutz (2008 [1962], pp. 216; Good, 1994, p. 231), uno de los supuestos de la vida cotidiana es que vivimos en el mismo mundo que las personas que nos rodean, y que el mundo que experimentamos y habitamos lo compartimos de manera intersubjetiva. La rueda es colectiva por principio, y es menester dejar las penas afuera: se accederá a la alegría siempre que uno esté acompañado, activo en la "conversación" que se da mediante el lenguaje de las cuartetas:

\author{
Yo sé lo que a mí me gusta \\ lo que sabia gustar: \\ juntarme con los alegres \\ que me sepan contestar.
}

Pues de hecho la soledad puede traer aparejada la tristeza:
A esta casa he llegado
a divertirme cantando
porque por a'i donde vivo
triste lo pasó llorando

(Ambas coplas fueron registradas en Molulo, enero de 2005).

Walter Ábalos, coplero de Molulo afincado en Tilcara, agrega:

6 Emborracharse, del quechua machasqa, que refiere a una borrachera festiva. Para más detalles véase
Saignes (1993). 
Una copla termina asi: "las coplas me van naciendo como agua de manantial" y sucede eso tal cual, en ese estado de éxtasis y de euforia, cuando todo el mundo comparte un repertorio de copla (Walter Ábalos, com. pers., febrero de 2011).

De tal manera que esta característica de acción conjunta se potencia, hasta el punto de que importa más la rueda que la unicidad de sus participantes. En una rueda de la que participé en Juella, en el desentierro del carnaval de Los Paseanderos, en 2019, luego de unas cuatro horas de cantar al son de las cajas, una coplera me acercó un nuevo vaso de Saratoga (preparado de vino blanco, jugo artificial y diversas frutas en rodajas); le pedí que me excusara porque sentía que no estaba pudiendo tolerar tanta cantidad de alcohol. Me respondió que era importante beber al interior de la rueda: “¡Tiene que beber!”, me dijo. Al preguntarle el porqué, me respondió: "Está bien que sea así, no es uno el que toma; la que toma es la rueda". Los copleros serían entonces las piezas necesarias del engranaje, no solo cantando y tocando las cajas, sino también bebiendo en demasía para que se produzca el advenimiento de la rueda con agencia propia, como una entidad única integrada por los cuerpos activos (que cantan, tańen y se embriagan) de copleras y copleros.

Ábalos confirma tal idea: "Si, es así. En una rueda de coplas la bebida es de la rueda. Y se procura que la misma no se termine. Por lo tanto, no debe faltar el aliciente para la garganta". Luego continúa con su argumentación: 'Cada coplero cuando arma su cuadrilla pierde su identidad personal. Y como grupo, hay algo que los une. Es maravilloso integrar y formar parte de una rueda de copleros" (Walter Ábalos, com. pers., abril 2020). El acto es el de compartir las mismas sensaciones: "Juntarme con los alegres/ que me sepan contestar", en tanto actividad creativa y social que involucra todos los sentidos.

Esta sensación de la organicidad de las ruedas, como si estuvieran dotadas de una corporalidad propia, se me ha presentado varias veces, sobre todo al verlas y escucharlas desde cierta distancia, cuando apenas se distingue el runrún de las voces ritmadas por el golpe de las cajas; cuando las siluetas de ponchos y sombreros en la penumbra hacen que uno pueda asemejarlas a una entidad única, como si se tratara de una salamanca (como me mencionó una vez Arias).

Esta sensación fue particularmente intensa en la víspera del desentierro del carnaval en Juella en 2019. La costumbre del lugar dicta que "Los Paseanderos", varones de la comunidad de distintas edades, premunidos de ponchos, sombreros, cajas y algunos erkenchos, van paseando de casa en casa hasta el amanecer, recibiendo un convite de bebidas por parte de los momentáneos anfitriones que los acogen. Durante un par de horas, mientras ayudaba a preparar el patio de la casa de los Quispe para la visita de los copleros, escuchaba a lo lejos el golpe a tierra de las cajas y los cantos a coro, como si se tratara de una única entidad sonora. Paulatinamente, íbamos escuchando de qué manera el runrún del coro de varones se acercaba a la casa hasta que fue posible divisar sus siluetas. Los mismos copleros incentivaron esta sensación de lo difuso, de lo indefinido: “¡Apaguen la luz!”, pidieron, no bien ingresaron al patio de la casa, que tenía encendida una única lamparita poco luminosa. “Nosotros somos a oscuro!”, insistieron. "Es que les queremos ver", respondió una de las anfitrionas. Una vez que se les dio el gusto, empezaron a cantar la primera copla: "Buenos días, buenos días..." (puesto que ya habíamos pasado la medianoche), durante una media hora, el tiempo que se terminó la bebida que la casa tenía para ofrecerles.

En todos estos casos, la ingesta de alcohol cumple un rol clave para la constitución simbólica del grupo o, de manera general, de una comunidad, en términos de una memoria común. Para Harvey, el consumo de alcohol en el marco de celebraciones, como la que estudió en Oncongate 
(en el sur peruano), genera cohesión social, garantizando la reproducción social y la protección de los poderes sobrenaturales a través del animu. Bugallo y Vilca (2011) han rastreado el concepto de animu para los casos de la puna y quebrada de Jujuy. Retomando lo indicado por Lanata para el caso de los Andes surperuanos, donde animu contiene gran parte del sentido de la voz quechua camac, que significa 'doble que anima' (pp. 3-4), los autores proponen:

El "doble", también llamado sombra, es lo anímico en los seres, que si se sale de la corporalidad debe ser restituido, para continuar siendo un ser animado, es decir poseedor de una esencia que se manifiesta a nivel de lo sensible [...]. En la región que nos atańe, el ánimu puede ser propio de un ser individual como de un grupo de individuos ligados por características o relaciones [...] (Bugallo y Vilca, 2011, p. 4).

Este animu también puede referirse al sonido, como ha reflexionado Stobart (1998), en la medida que la animación es una cualidad atribuida a los seres vivientes, como el rayo, el agua que corre o ciertas peñas provistas de una energía especial (Stobart, 1998, p. 581). "Esto sugiere que la manipulación del sonido, por ejemplo en la música, se puede entender como equivalente al control de las fuerzas vitales" (Stobart, 1998, p. 582). En suma, es esta animación la que crea grupos de individuos activos, como los que yo escuchaba llegar en Juella, que producían un sonido con una animación específica de voces, cajas y erkenchos, con el "aliciente" del alcohol.

Una de las particularidades de la experiencia intersubjetiva de los copleros y copleras, mediada por el canto y el festejo, es que no se reduce al vínculo con otros seres humanos, sino que suma a "otros" no humanos. Lo social, en estos casos aparecería bañado de un sentido más amplio y complejo, una socialidad de tipo intercultural y en distintas dimensiones, retomando la propuesta de Bugallo y Vilca (2011):

Entendemos entonces lo intercultural como la apertura de nuestras categorías moderno/occidentales para comprender/entender el mundo andino, y en especial los complejos elementos que están interactuando entre sí, y no sólo de modo causal, que desembocan en un desequilibrio. Será necesario insistir en que espacios, personas, seres poderosos (actuales y potenciales), plantas y animales están íntimamente relacionados" (Bugallo y Vilca, 2011, p. 13).

Los copleros y copleras se relacionan con seres poderosos como la Pachamama, la Sirena y San Carnaval, a quienes hay que pagarles con libaciones, a cambio de abundancia en la producción y alegría en las fiestas. La relación social intersubjetiva continúa con los animales de la hacienda en las marcadas y seńaladas: se les dedica coplas, se les convida coca y chicha, se los enflora y enharina, en una búsqueda de igualdad de condiciones entre humanos y animales. Esta relación intersubjetiva también se da con espacios específicos del paisaje, tales como mojones carnavalescos, ojos de agua, cascadas, vertientes y algunos cerros: espacios de una energía especial a los que hay que saber reverenciar, chayando. La relación intersubjetiva continúa de manera notable con la caja y el erkencho, a los que se los cuida amorosamente y se les cantan coplas:

\author{
Esta cajita que toco \\ tiene boca y sabe hablar. \\ Solo le faltan los ojos \\ para ayudarme a llorar.
}


Como la caja, que "tiene boca y sabe hablar", el erkencho también tiene vida propia. David Quispe, en Juella, me mencionó que la melodía que hace el erkencho canta: "come, cague, peee" (David Quispe, com. pers., febrero, 2019), destacando sus procesos fisiológicos similares a los nuestros. Finalmente, esta socialidad involucra de manera global a la rueda coplera. No por nada es habitual que cualquiera que se sume siempre arranque con alguna copla con la que pide permiso de ingresar, no solo a los intervinientes, también a la rueda misma. Beberá y torcerá por izquierda, quebranteando al cantar, para dar y mantener la vida de la rueda.

Por último, al conversar con copleras y copleros, en otros momentos, antes o después de la realización de la rueda, he escuchado una aseveración recurrente que se puede resumir del siguiente modo: que la tradición de la copla contribuye a la cohesión en torno a una identidad colectiva, cimentada además en una conciencia étnica. Esta cohesión permite la reproducción de prácticas y saberes entendidos como ancestrales, que deben ser preservados y transmitidos, pues según un discurso extendido "se corre el riesgo de que desaparezcan", como ha observado también Mennelli (2010a).

Este esfuerzo por expresar una cohesión en torno a una identidad coplera no suele aparecer mientras los integrantes de la rueda "están en eso", in situ, puesto que no necesitan enfatizar tal característica, entendida como un valor, entre ellos. Ese "nosotros" se define a posteriori, ante un otro que viene de afuera (yo) y que pregunta. Puede darse una consistencia de ese acto identitario en medio de la rueda, pero siempre que exista un otro definido como distinto (un turista que manifiesta interés, un investigador). Esto me ha ocurrido varias veces en medio de un espectáculo, encuentro o festival, casi siempre relacionado con el turismo, como el inicio del Enero Tilcareńo, en la Plaza Grande de Tilcara, donde se suele invitar a copleros y copleras, para enfatizar "una de nuestras tradiciones más queridas", como he escuchado decir a un locutor y maestro de ceremonias del municipio.

Cuando se les consulta, los copleros y copleras suelen asumir su práctica como la más cercana a una ancestralidad deseada, en comparación a la mezcla que se atribuye a otros tipos de prácticas festivas como los carnavales de comparsas y de fortines de los pueblos de la quebrada y de la puna, así como al empleo de otros instrumentos musicales y por tanto de otras sonoridades (sobre todo las bandas de bronces y las orquestas con instrumentos electrificados), o géneros musicales y dancísticos, en un amplio espectro que va de los ritmos del altiplano boliviano (saya, morenada, tinku, entre otros) a la cumbia chicha, villera, norteńa o boliviana.

\section{3. "La Salamanca es la copla": torsiones, disidencias y subversiones}

Para Schutz, la actitud natural es no dudar de lo aparente: aceptamos el mundo y sus objetos tal como aparecen, hasta que se establezca una prueba en contrario (Schutz, 2008 [1962], pp. 214, 216; Good, 1994, p. 234). La epojé específica en este ámbito de sentido genera una forma específica de conciencia, de espontaneidad y de experiencia del si-mismo, distinta a la del mundo del ejecutar, que consiste en suspender la duda. Para quienes ingresan a la rueda, esa suspensión de la duda puede fallar, el mundo de la conciencia cotidiana se subvierte y se empiezan a habitar otros mundos de experiencia.

Respecto a este punto, Mariano Mamaní, coplero nativo de Molulo, ante la pregunta sobre la salamanca me responde: "la Salamanca es la copla", planteando una analogía directa entre ese mundo difuso con la rueda de coplas. Esta definición tan certera me recuerda, al mismo tiempo, otra situación vivida: ante unos segundos de filmación que habíamos realizado de una 
rueda en San Francisco en marzo de 2005 para el documental Davueltando (registro de Moreau basado en la investigación y guion de Ábalos y Sánchez Patzy, 2006), en los que puede verse a la gente desde lejos, de noche, con una iluminación muy tenue, confiriendo una sensación casi espectral al tumulto y a los sonidos difusos de los cantos y las cajas, Quintino Arias me dijo: "Eso es la Salamanca", refiriéndose al imaginario popular de este espacio, que se piensa como un lugar extraño donde la gente festeja sin frenos en un lugar neblinoso, bizarro y especular, muy cercano a lo que hicieron los Paseanderos de Juella al llegar a la casa de la invitación que he comentado (cf. supra) pidiendo que se apagaran las luces ("Nosotros somos a oscuro").

En todos los casos que describo, se desdibujan los cuerpos como cuerpos, las fronteras entre unos y otros. No se resigna lo singular; se respeta esa singularidad, porque cada participante de la rueda tiene la palabra, tiene sus coplas, sus tonadas, su estar; pero los cuerpos se van indefiniendo, en torno a producir este empuje, esta animación al interior de la rueda. Algunas coplas de carnaval hablan, por cierto, de la Salamanca:

\author{
Ayer canté en la frontera \\ hoy canté en la Peña Blanca \\ si quieres cantar conmigo \\ perdete a la Salamanca \\ (Copla común en la quebrada y valles orientales de altura).
}

Me detengo en ese "si quieres cantar conmigo/perdete a la Salamanca", cuya invitación implica un sacrificio: dar el cuerpo perdiéndolo, para entregarlo a la rueda o la Salamanca, junto con los otros copleros y copleras. Esta percepción tiene resonancia con la etnografía de Abercrombie sobre los k'ulta (en Oruro). Allí el autor sugiere que macharse hasta la intoxicación sería una "ofrenda de cuerpo" necesaria hacia las deidades. Implicaría sacrificar el cuerpo, hartándolo, de manera tal que quien se macha -el pasante de la fiesta- tome para sí un atributo del Dios: "la capacidad ilimitada, la saciedad englobante". El pasante toma así el lugar de los dioses, al ofrecer esta demostración de prosperidad, un atributo del dios (Abercrombie, 1993, p. 102).

Otro aspecto que ya he mencionado y que me interesa plantear con más detalle, relacionado con la subversión del sentido común y lo cotidiano, tiene que ver con el hecho de que la rueda se mueve de manera inequívoca en la dirección contraria a las manecillas del reloj. Me he preguntado muchas veces si existe algún vínculo con la manera en que en diversos lugares de los Andes se tuerce un hilo especial con propiedades medicinales, el denominado hilo lloqe. ${ }^{7}$ ¿Será posible equiparar la dirección del torcido del hilo lloqe al movimiento de la rueda? Se lo pregunté a Ábalos, y esta fue su respuesta:

Efectivamente en una rueda de copla se gira en dirección contraria a las agujas del reloj, al igual que para sahumar o cuando se davuelta con la hacienda en el corral después de una marcada; para sahumar cuando se cura de susto y también para ayudar en las contracciones de parto y nazca el bebé. Nosotros decimos a la derecha. En el hilado común se hila a la derecha y se tuerce a la izquierda. En cambio el hilo lloqe se hila a la izquierda y se tuerce a la derecha. Hilar a la izquierda no es nada fácil. En este sentido solo el torcido del hilo lloqe se hace en el sentido que gira la rueda de copla, en dirección contraria a las agujas del reloj. En el despacho de la hacienda [el momento final de la marcada o señalada de los animales] dicen que es para

7 Lloq'e, lloqe, es una vocablo quechua que significa izquierdo o zurdo (Rosat Pontalti, 2009, p. 636). 
la suerte. El girar a la izquierda sería de malos augurios y la suerte se podría volcar (Walter Ábalos, com. pers., abril de 2020).

En estudios sobre tejedoras en las tierras altas de Jujuy y Salta (Rolandi y Jiménez, 1985), así como en otras investigaciones sobre la producción sonora (Sánchez Patzy, 2006), aparece con fuerza esta lógica de las vueltas y la torsión. En el mundo andino, como ha sido ampliamente estudiado, hay una preeminencia de lo curvo, lo serpenteado o zigzagueante, de todo aquello que da vuelta, como atributo de lo bello. Tal idea se plantea no solo para los diseńos visuales, sino también para lo sonoro y lo musical (véase por ejemplo Stobart, 1998). Se trata, en una palabra, de una estética deseada. Por ese motivo, no solo lo sinuoso en lo musical y lo textil es bello, sino que, para el caso del textil, lo sinuoso tiene propiedades curativas, como sacar el mal aire, el aire malo. Protege contra los malos espíritus de quien porta la pieza tejida, es fundamental su uso en el mes de agosto, que se considera trae consigo una energía especial, como dice la copla:

\section{Yo soy como el mes de agosto \\ traigo viento y remolino \\ dando vuelta, dando vuelta \\ como piedra del molino.}

De esa energía arremolinada hay que protegerse. La rueda tuerce en la dirección del hilo lloqe (como también ocurre con el acompañamiento de la hacienda en el momento del despacho, cuando se sahúman las esquinas de una casa o a los nińos para curarlos del susto, y cuando se ayuda a las mujeres en las contracciones de un parto), porque porta el sentido de lo excepcional. Plantea el contacto con las fuerzas genésicas ligadas a la fertilidad y la reproducción de las especies, y de manera más general a una energía vital que anima a través de la alegría. Al tiempo de ser una estética deseada, "quebranteando", la rueda cura y protege.

Por otra parte, una coplera mencionó que el canto colectivo de la rueda se asemeja al balido de las cabras. ${ }^{8}$ He escuchado algo cercano en los valles orientales, donde se relaciona el sonido que emite el erkencho con el del mugido de las vacas y las cajas con los sayales, montículos de guijarros desprendidos de las paredes de laja que, al entrechocar con el concurso del viento, producen un sonido parecido al del palo de lluvia. Una copla propia de los valles orientales dice:

\section{Si esta caja fuera buena \\ Sonara como un sayal. \\ A los mejores cantores \\ Yo les hiciera callar.}

En este sentido, el ser humano es interpelado por un sonido proveniente de la naturaleza (una vaca, una cabra, un sayal) y puede aprovechar su potencialidad inherente, en la medida que cumpla con las reglas al momento de construir el instrumento y de realizar las ceremonias específicas posteriores, para que la "caja toque por su propia cuenta", como ocurre con el entrechoque de los guijarros del sayal que son "tocados" por el viento. ${ }^{9}$ Solo así se podrá conseguir el mayor nivel estético posible del instrumento.

8 Le debo este dato a Suzanne Gruca, com. pers.

9 Estas ideas también son aplicables, según me han explicado, a los wankares, grandes arenales de la puna. Se dice de ellos que suenan solos, en días de mucho viento. Por ese motivo, se los considera espacios de una energía especial. 
La epojé específica en el ámbito de sentido de la rueda de coplas genera, además, un contradiscurso propio del Carnaval, tal como lo estudió Bajtin (2005), el cual se desarrolla en los márgenes de los discursos sociales hegemónicos. Es particularmente notable lo que ocurre con el discurso de las coplas de las mujeres, puesto que cantar y bailar ininterrumpidamente son acciones que las resitúan fuera de los contextos domésticos privados. Son las copleras, como han estudiado Mennelli (2010a y 2010b) y Mirande (2010 y 2018), quienes alzan sus voces para entonar cuartetas de gran fuerza subversiva en el contexto del carnaval:

Casada, soltera soy,

tengo las ganah 'i joder;

$y$ en ausencia de mi dueño

soy dueña de proceder (Mirande, 2010, p. 166).

La copla muestra ese pasaje de la vida doméstica a una conciencia del ser que implica imaginar alternativas al mundo establecido.

\title{
4. "Nos hemos encarnizado": la subversión de la percepción cotidiana del tiempo
}

Schutz propone que otra característica del mundo cotidiano consiste en la experiencia de tener una perspectiva temporal común intersubjetiva que compartimos con los demás (Schutz, 2008 [1962], p. 207; Good, 1994, p. 232). La experiencia dentro de la rueda tiene una perspectiva temporal específica, que, en un punto, no traspasa los límites del mundo del ejecutar. Muchas coplas no muestran una pérdida del sentido temporal, pues más o menos se sabe que el festejo tendrá un fin: el amanecer -o más generalmente el entierro del carnaval- y con esto se retornará a la vida cotidiana:

\section{Yo soy el que me amanezco \\ cierro la noche cantando, \\ mi caballo con mi caja \\ se amanecen trasnochando.}

O también:

\author{
Pobrecita mi cajita \\ junto conmigo padece, \\ desde que cierra la noche \\ hasta la hora que amanece \\ (Coplas recopiladas en Molulo, febrero de 2005).
}

Si bien no se elimina la irreversibilidad del tiempo estándar ("sigo envejeciendo", diría Schutz), en la rueda propiamente dicha, la percepción cotidiana del tiempo sí se subvierte, tal como han observado diversos estudios. La manipulación de la realidad temporal o el tiempo es propia de las actuaciones culturales, en tanto son eventos temporalmente limitados -tiempo fuera del tiempo- (Stoelje y Bauman, 1988; Bauman, 1992). Ábalos plantea algunas ideas centrales respecto a este punto:

Es como que te sales de la vida real, te olvidas de todo. Llegas a un estado de ¿cómo le llaman? “Encarnizado!”, “'Nos hemos encarnizado!”. De hecho con el siku también: 
nos encarnizamos y nos perdemos ahi en ese mundo, en ese encarnizarse. De hecho ahora he vuelto a sentir eso: encarnizarse cantando. Te olvidas de todo y estás viviendo solamente ese momento (Walter Ábalos, com. pers., febrero de 2011).

La metáfora del encarnizamiento, además de remitir a un ensañamiento lúdico con un otro (bien sea un sikuri o un coplero), me lleva a pensar en la imagen de la carne y todo lo que de ella deriva. ¿ Se trataría de una suerte de verbo encarnado unido por definición a la naturaleza humana que imbrica cuerpo/mente y sujeto/mundo, como reversos de una misma cosa? La metáfora merleau-pontiana de "la carne del cuerpo" como la "carne del mundo" que da cuenta de la reversibilidad de lo sensible y lo sensitivo, de la imbricación del lado sensible que puede ser visto, tocado y escuchado, y también su lado sujeto, que ve, toca y escucha, cobra una gran potencia en este relato. Ábalos continúa:

W.A.: El encarnizarse también a veces pasa por el desafío también frente al otro que está a tu par, ¿no?. Yo me encarnizo con vos porque quiero superarte, ganarte cantando, ganarte tocando, ¿no? entonces tú también te encarnizas conmigo y es como un ida y vuelta pero en la música, tocando un siku o bien cantando. De hecho pasa mucho eso...

R.S.: ¿Y en ese estado se pierde la noción del tiempo?

W.A.: Exactamente. Hasta te olvidas de las horas, esto es increible ¿no? uno no puede entender cómo puede una persona amanecerse cantando tantas horas. Se empieza ocho de la noche y terminas a las seis de la mañana. Y sigues con voz, jes increíble! Pero solamente uno lo entiende cuando uno lo hace, ¿no? Ha pasado una hora para vos, pero ya es de madrugada... Te das cuenta y no puede ser. Porque te has perdido toda esa noción de tiempo, te has olvidado totalmente (Walter Ábalos, com. pers., febrero de 2011).

Luego de horas de cantar y escuchar activamente, "quebrantear" e ingerir importantes cantidades de alcohol -probablemente también por la hiperventilación que significa cantar durante horas con una respiración acompasada al toque de las cajas, todo sumado al movimiento repetitivo del cuerpo-, la experiencia de ese mundo indeterminado e igualmente espectral, no solo para el que canta sino también para el que escucha, define las fronteras del tránsito por ese tiempo y ese espacio hasta el momento del amanecer. De tal manera que perder la referencia del cuerpo, como he mencionado, es también perder la referencia del tiempo.

\title{
5. "Quebrantiando, quebrantiando": bifurcaciones de la conciencia y estéticas deseadas
}

Schutz indica que la realidad del sentido común tiene una forma específica de conciencia: atención vigilante y activa, en estado de alerta ([1962] 2008, pp. 201-202, 216; Good, 1994, p. 234). Respecto a este punto, pareciera que, por un lado, la conciencia se aleja de la atención plena en la rueda, es decir, esta se distrae, se bifurca, se carga de otros sentidos, en buena medida por la experiencia de macharse, como puede leerse en esta copla:

\author{
Caramba que me'i machado \\ tomando un vaso 'i cerveza \\ he perdido mi caballo \\ causa mi mala cabeza \\ (Molulo, febrero de 2005).
}


Arias me comenta que el buen coplero o coplera mantiene conciencia sobre el manejo de su cuerpo, del uso de la garganta:

Las coplas casi pueden ser las mismas, nada más que lo que cambia es la tonada, la forma de manejar la garganta. Es la tonada que el ritmo de copla, de la garganta, en verano es más rápida, más alegre, más contagiosa y se la canta en rueda y muchos los cantan medio bailando, bailando, llevando el ritmo que mucho que van a verlo como canta esa persona, canta, tiene una garganta bárbara y lo lleva el ritmo medio este... al ritmo va moviendo el cuerpo, y como decian aquellos amigos mios antiguos: ese canta quebrantiando, quebrantiando; medio como si estuviera bien macha'o asi, se ladea, para acá, para allá llevando el ritmo y es bonito verlo cantar así, pero el tipo está bien, la persona está bien, es su forma de divertirse, de cantar, de contagiar el ritmo, su copla, su forma de ser, y por ahi, a veces, de vez en cuando, pegar un grito, un grito de alegría (Quintino Arias, com. pers., abril de 2005).

El mismo coplero me hace un comentario muy gráfico y expresivo sobre el uso de la garganta:

Allá es como que usás todo tu ser, todo tu garganta. Empezás a cantar en grave y llegás a un punto de falseta, a donde se limita tu garganta y volvés a lo normal, en una copla que te puede durar 30 segundos. Y para mi es todo práctica, esta gente de ahi de Pampichuela, San Lucas, Santa Bárbara, ellos te cantan asi nomás con falseta, con falseta y bien pronunciado ese... esa garganta de gargantear mientras cantás. Porque has visto aqui en la zona Quebrada o en Salta, siempre largan la garganta, tienen garganta, voz de garganta, pero no hacen el garganteo como se escucha en la zona del Valle, la garganta que va vibrando la voz mientras va cantando. Y levanta tan bruscamente desde lo grave a la falseta que..., de lo grave a lo agudo, sube y baja, sube y baja, pero, este, bien sincronizado, bien vocalizado, que si un maestro tiene que ir a imitar, yo séque le va a costar un montón, un músico por más músico que sea, manejar esa garganta, no: ese tiene que nacer (Quintino Arias, com. pers., abril de 2005).

Esta apelación al bajar y subir para volver a bajar, este ida y vuelta como explicación sobre la externalización de los sonidos vocales, que da cuenta del uso de portamentos, inflexiones y quejidos como tránsito de una nota a otra, yendo y viniendo a otros sonidos de la escala, sobre todo la octava aguda, tiene que ver con una voz apuntada tempranamente por Vega (2010 [1944], p. 120): kenko, cuyo significado remite a lo curvado o lo sinuoso -según la traducción de Bertonio: "es una cosa tuerta que da vuelta" (2006 [1612], p. 669)-. Esta idea manifiesta una estética deseada, presente en diversas regiones de los Andes, como destaca Stobart (1998). Si bien en mi experiencia de campo nunca he escuchado el empleo de esta voz, sí es corriente el uso del verbo 'davueltar' cuyo sentido es bastante próximo (Sánchez Patzy, 2006).

Podría ocurrir que la conciencia accediera a una dimensión aún más activa y plena que la del sentido común:

W.A.: En esa euforia como que hay otro sentido, ¿no? que te hace recordar las coplas, y no te olvidás las letras. En otro estado no pasa, estás pensando, la meditás, "¿qué voy a cantar?", "no me voy a acordar"... Pero en ese estado te salen las coplas como agua de manantial. Y también hay otro componente interesante: en ese estado sale la parte expresiva, ¿no? La más bonita que uno puede ver. Esta idea de lo que decía Quintino del 
"quebranteando".. toda esa cosa del movimiento, de la mueca. Que es una soltura de todo el cuerpo, ¿no? Creo que en ese estado se da igual cuando se agarran los sikureros, cuando se encarnizan aparece toda la parte expresiva, aparece toda la fuerza corporal total, es muy bonito ver eso... además la forma de agarrar la caja, la forma de ejecutarle, todo se mezcla ahi en ese momento. Por ahi en otro momento, quizás al no llegar a eso, estás más frí ¿no? aunque cantás bonito suena lindo tu voz, pero no hay esa parte expresiva, hay temor en olvidarte las letras, las coplas y todo... (Walter Ábalos, com. pers., febrero de 2011).

En esta narrativa, se expresan los recursos de los que se valen copleros y copleras al momento de coplear: se coplea con el cuerpo todo, solo así "las coplas van naciendo como agua de manantial". En ese sentido, bifurcar la conciencia, abrirse a otras experiencias permite acercarse a la experiencia de lo bello.

\section{6. "De corazón ancestral": ancestralidad y luchas identitarias}

El mundo cotidiano, afirma Schutz (Good, 1994, p. 234; Schutz, 2008 [1962], p. 216) tiene una forma predominante de espontaneidad provista de sentido, basada en un proyecto y caracterizada por la intención de realizar lo proyectado mediante movimientos corporales que se insertan en el mundo externo. Los proyectos parecen ponerse en pausa en el momento de la rueda. Pero solo si uno se compenetra totalmente y todos también deciden hacerlo; cuando uno "se deja llevar" por la cadencia de la copla, por el golpe a tierra de la caja, por el vaivén del cuerpo, por la rueda que gira, por el alcohol que embriaga. Claro que esto, según Walter Ábalos, no ocurre siempre:

Cuando pasa eso por ahi no hay tantos lios, no hay problemas que pueden aparecer. La misma gente se olvida. Lo interesante es que lleguen a ese estado todos, ¿no? Entonces no hay esas discusiones que siempre aparecen por el alcohol y todas esas cosas, ¿no? Cuando no hay esa actitud de euforia de todos, aparecen los problemas, las discusiones. No siempre sucede, pero cuando sucede es increíble. Todos terminan cantando y enfiestados y no hay problemas (Walter Ábalos, com. pers., febrero de 2011).

Sin embargo, no se pone en pausa cierta fantasía de futuro, y el interés consiguiente de llevarlo a cabo, en lo que respecta a roles sociales dentro de una configuración cultural en un sentido amplio. Es interesante observar, por ejemplo, que la copla que se canta en el contexto de una marcada o seńalada de los rebaños nunca deja de considerarse un "trabajo". De tal manera lo concibe mi entrevistado:

W.A.: Yo entiendo que el cantar coplas es una actividad más, un trabajo. Porque el dueño de casa, en retribución, ofrece a los copleros bebidas y comidas. Dice una coplita:

Asi cantando y bailando,

chichita me estoy ganando.

Aquellos que están sentados,

se le estarán acabando.

Así pues, como evaluación de las posibilidades prácticas basadas en experiencias aceptadas y fuera de cualquier cuestionamiento, la dimensión de trabajar, de pagar en las señaladas y marcadas, no se pierden. 
Como ya he mencionado en el punto 2, muchos copleros y copleras despliegan sobre sí mismos un discurso de identidad étnica fundado en una ancestralidad, “[...] que, según como se lo considere, puede comportar rasgos esencialistas, pero que también cumple la función política de enmarcar sus acciones, integrando su pasado y su proyección hacia el futuro" (Mennelli, 2010b, p. 264). Coincide con Abercrombie (1992), quien ha destacado que el estudio de las festividades en los Andes permite hacer lecturas de ciertos dilemas o conflictos étnicos y de clase. La etnicidad en la rueda de coplas se manifiesta, entre otras cosas, en la presencia de wiphalas, cuyo uso durante el carnaval -como ocurre con integrantes de las Cuadrillas de Coplas del municipio de Humahuaca-, implica un sentido político en tanto se vincula con las luchas reivindicatorias de los pueblos originarios y es omnipresente en la agenda de las Comunidades Indígenas de Jujuy. Con la emergencia de movimientos políticos basados en la valoración de una ancestralidad de raíz indígena andina, esta percepción parece acentuarse.

La copla como un medio que habilita a la transmisión hacia afuera de una identidad étnica, de un mensaje de contestación o de resistencia, tiene como ejemplo más importante al Encuentro de Copleros de Purmamarca, creado con el retorno a la democracia, en 1983. Reúne todos los ańos a centenares de copleras y copleros, semanas antes del desentierro del carnaval. No es un encuentro relacionado directamente a la celebración de fertilidad de la hacienda y de los productos de la tierra, pero sí a la algarabía precarnavalesca. Por ese motivo, este encuentro se nutre de otras características. Selva Vilte, una de sus creadoras, comenta el sentido político del canto que fue el vector de la creación de este encuentro:

Surgió después de la dictadura militar que asoló al pueblo argentino, que nos llevó a dividirnos y escondernos, pero después dijimos que no podemos permitir que nos callen, un pueblo que no canta es un pueblo dominado, entonces cuando aparecen los primeros signos de la democracia decidimos hacer este Encuentro para volvernos a reunir en las ruedas y así fue haciéndose año a año y seguirá con la fuerza de nuestros jóvenes y de todos los que nos colaboran en cada edición (Pamela López, El Tribuno de Jujuy, 12 enero 2020, los destacados son míos).

Son justamente los y las jóvenes quienes pueden entonar versos con un sentido altamente político, como estas dos estrofas que he escuchado cantar a la joven bailarina y coplera purmamarqueña Daniela Cazón:
Yo soy cantora del pueblo
y a mi no me han de callar,
$y$ aunque me lleven a rastras
mi memoria quedará.
La vida a mi me ha enseñado
ser libre en mis pensamientos.
Yo me cansé del silencio
cruzar fronteras de miedo. ${ }^{10}$

\footnotetext{
10 Coplas cantadas en el encuentro “Grito en el cielo, fogón de la memoria: Las Tonadas de Pascua”, evento organizado por el Instituto Interdisciplinario Tilcara, FFyL-UBA el 3 de mayo de 2019).
} 
Cazón entonó estas coplas en un encuentro realizado en Tilcara. No se trataba de una rueda en un sentido tradicional, sino de un evento de valoración de un repertorio ante un público con interés de conocimiento. Fue recurrente escuchar el sentido identitario profundo que cada coplero o coplera atribuye a la copla. Al preguntarle posteriormente por qué eligió esas coplas cuando llegó su turno, me respondió: "La primera, porque viviendo en Purmamarca, sintiendo a mis abuelas de ahí, sintiéndome que pertenezco al lugar, me hizo sentir identificada. Y es una copla de Marina Vilte [maestra purmamarqueña y delegada sindical desaparecida por la dictadura cívico-militar argentina en 1976] que tiene la historia de que la cantó en la carcel. Doña Bety [hermana de Marina, y otra de las organizadoras del encuentro de copleros] la canta y me emociona mucho". El compromiso con la memoria se hace evidente en su emotiva descripción.

La segunda copla, continuó Cazón, “es de Bicho Díaz [músico humahuaqueño que incursionó en sonoridades y poéticas novedosas basadas en la música tradicional jujeńa], con quien compartimos en carnaval. Escuchando esa copla en una canción del primer casete, me gustó mucho y también me siento identificada para estos tipos de transformaciones sociales que vivimos las mujeres". A su manera, las respuestas de esta joven coplera manifiestan los caminos diversos de la copla, que en este caso provienen, con sutiles modificaciones, de una chacarera -"La Viajera"- grabada por un músico popular. Es destacable el hecho de que los versos que hablan de cansarse del silencio, de ser libres de pensamiento para cruzar las fronteras del miedo resuenan en esta coplera en la lucha feminista de los últimos ańos en Argentina, que mi entrevistada precisa con otra copla de su autoría:

\section{Somos negras feministas, de corazón ancestral. Negras mujeres andinas con gran poder natural.}

En todos estos casos, es clave el contexto en el que se cantan coplas reinvindicativas o feministas, como afirma Mariana Castro, bailarina humahuaqueña, integrante de la Nueva Cuadrilla de Cajas (y Erkenchos) de La Banda, de Humahuaca:

$Y$ ahi yo hago una diferencia, porque yo como que me contextualizo, si estoy con las chicas del movimiento [feminista], comparto algunas coplas en ese estilo y si estamos en otro contexto prefiero que no, prefiero como que se vaya generando un espacio más genuino de lo que la gente del lugar, o las mujeres, van sintiendo y pensando ellas al margen de una teoría (Mariana Castro, com. pers., mayo 2020).

En la reflexión de Mariana aparece subrayada la importancia de contextualizar las coplas, de entender "el lenguaje" común, para que no se produzca una imposición.

En el encuentro mencionado, esta coplera trazó una interesante descripción de lo que ocurre con la identidad coplera, apelando a su propia biografía:

\section{[...] Creo que es tan fuerte la copla que brota, brota, y brota alrededor de la gente que la canta. Como una copla que recopiló Leda Valladares,}




\section{La copla baja del cerro \\ como agua del manantial, \\ trayendo memoria antigua \\ de nuestro pueblo ancestral.}

$Y$ bueno, uno se va identificando, pudiendo reconstruir la identidad que a nosotros por ahi nos han dado..., nos han aculturado de una forma muy fuerte, con la escuela, con la imposición de una cosmovisión occidental que bueno... ha venido por ahi a desvincularnos de la tierra [...]. Nosotros no cultivamos la tierra, no tenemos esa conexión con los ciclos vitales que hacen que toda esta copla sea la que dirija un poco ese ciclo también ¿no? Bueno, entonces todas estas cuestiones que van entretejiéndose en la cultura, que van produciendo que nosotros nos reconectemos con esa fuerza vital, creadora de la Pachamama va a estar siempre. Y es por eso que, bueno... en mi caso no tuve una madre cantora que me pudiera transmitir este legado, me lo transmitieron estas abuelas, estas mujeres que están aqui presentes [se refiere a las copleras más veteranas de la Nueva Cuadrilla]. A los 14 años, mi maestra de folclore me llevó a la cuadrilla, y ella a nosotros con mi amiga Daniela con la cual compartimos ese espacio de muy chicas, de intentar animarnos a cantar, de pronto no tener una caja, ir acercándonos de a poco..., pasar los años, ya pudiendo agarrar una tonada. Porque es verdad, cantábamos asi: la, la, la, la [...]. Claro, nosotras no teníamos esa posibilidad (Mariana Castro, com. pers., mayo 2020).

Son notables todas las aristas que despliega esta narrativa, que arranca apelando a una copla recopilada por la tucumana Valladares, figura clave en la difusión del canto con caja en la Argentina. Esa copla ańade a su flujo la memoria antigua; ya no solo la memoria del que las canta sino del ancestro, cobrando una dimensión que va más allá del nosotros, que nos antecede de manera omnisciente.

Estas narrativas identitarias que reelaboran la experiencia de la copla, por fuera de la rueda misma, muestran las maneras distintas con las que muchos y muchas jóvenes en los últimos años se acercan a esta tradición. Para Good (1994)

[...] sería un error no tomar en cuenta el hecho de que el cuerpo social y político son también fuente y medio de la experiencia. Si la experiencia es íntersubjetiva y se desarrolla en diálogo con quienes se encuentran en el ambiente social, este diálogo y las estructuras mediadas por éste son también constitutivos de la experiencia (p. 10).

Así, la búsqueda personal de Mariana por "reconstruir" su identidad y su experiencia, como ella afirma, expresa de manera vívida lo que ocurre con una generación que nació en los conglomerados urbanos de la Quebrada, que son hijos y nietos de agricultores y pastores, pero que ya no cultivan la tierra ni pastorean la hacienda. Su conocimiento sobre los calendarios agropastoriles y las constelaciones sonoras afines como el canto con caja, le llega de otros modos, o a veces, se interrumpe por falta de transmisión de ese "legado". La "reconexión con la Pachamama” incorporará entonces un bagaje de intereses y conocimientos que provienen de otras instancias formativas, como la escuela, la universidad o de grupos artísticos cuya aproximación a las tradiciones se produce desde la experiencia urbana. La narrativa de estas dos jóvenes copleras muestra los nuevos intereses que se van dando relacionados con la copla en los 
últimos años, y los proyectos identitarios y de reivindicación de los derechos de género y de los pueblos indígenas de Jujuy.

\section{...Y vuélvase a cerrar}

He intentado con este trabajo abrir interrogantes que propendan a pensar las experiencias sensitivas en la práctica de la copla. He procurado que la principal atención esté centrada en el cuerpo de los copleros y las copleras como fuente creativa de la experiencia. En ese sentido las relaciones entre la experiencia corporal, el significado intersubjetivo, las estrategias narrativas que reflejan y reelaboran las experiencias de la rueda, y las prácticas sociales que canalizan el comportamiento de sus participantes han sido básicos para mi exposición.

He desgranado las características de la multilateralidad dinámica de la rueda, a la que cada participante ingresa con su tonada propia, pero que, una vez dentro, marca una fina arquitectura entre lo singular y lo colectivo, de manera tal que al acompańar con la caja el canto propio, se acompańa el canto de todos. Esta multilateralidad provista, además, de una experiencia específica de los cuerpos que, "quebranteando", tuercen la rueda, generan momentos de communitas con una animación propia que alegra y que, al mismo tiempo, produce belleza.

Haber aplicado el concepto fenomenológico de "epojé" al mundo de vida coplero, y señalar el conjunto de significados que he obtenido en la experiencia dentro de la rueda, me ha permitido sistematizar los modos en que la conciencia se aleja de la atención plena, se bifurca y se llena de sentidos disímiles. Si la actitud natural es aceptar el mundo y sus objetos como aparecen, para quienes ingresan a la rueda la maniobra de suspensión de la duda les suele fallar. La aceptación del mundo deja de ser la misma, el mundo se experimenta distinto, se olvida de uno y empieza a cobrar más importancia la rueda que la suma de todos los participantes. Uno puede casi ofrendar su cuerpo a la rueda, macharse hasta la intoxicación. La experiencia cotidiana se subvierte, como afirma todo coplero o coplera que ingresa a la rueda. La experiencia del canto, de la corporalidad de los copleros y copleras, que tuercen cuerpo y rueda, que beben, de un nosotros intersubjetivo, de ese "nosotros estamos", y el vínculo intersubjetivo con "otros" no humanos: con los seres que habitan la Salamanca, con la hacienda a la que se le canta coplas; con la caja y el erkencho, con la rueda misma.

Como se ha visto, partiendo de un inventario de códigos, formas y escenas, una comunidad construye actuaciones culturales, creando para los individuos la oportunidad de experimentar e intensificar su identidad social, al mismo tiempo que, en situaciones especiales, subvierten algunas estructuras sociales, permitiéndose imaginar alternativas a la experiencia de lo cotidiano, como ocurre con la lectura que puede hacerse de muchas coplas femeninas. Muchas otras estructuras se mantienen a posteriori, como los proyectos étnico-políticos que dan cuenta del estrecho nexo entre el tiempo extraordinario de la fiesta y el día a día, reproduciéndose los engranajes de la jerarquía social y la conflictividad. Pero, al mismo tiempo, participar de ese momento extra-ordinario puede implicar actos de desafío y la reemergencia de identidades indígenas.

La copla es una experiencia creativa en constante movimiento. En este trabajo me he circunscripto a su uso más tradicional, relacionado a las marcadas del ganado, las señaladas de los rebaños, o el entierro y desentierro del carnaval, aunque he realizado un breve repaso de lo que ocurre con la copla en contextos distintos, donde pueden aparecer coplas que plantean 
disidencias, o que ponen en cuestión determinadas estructuras sociales. Es en esos casos que aparece con fuerza la narrativa de una identidad coplera. Queda como tarea a futuro ver con mayor detalle lo que ocurre en estos nuevos espacios y tiempos; qué ocurre cuando la ingerencia del mercado y de las políticas turísticas provinciales son mayores y que, de hecho, tienen a las copleras y copleros como un atractivo especial. Es indispensable, en este panorama, profundizar en los modos de circulación y de (re)apropiación de los mismos discursos desde fuentes institucionales, tanto de las comunidades asumidas como indígenas como de la propia agencia del Estado provincial y las empresas turísticas privadas.

También resulta interesante analizar la experiencia coplera mediatizada por las nuevas tecnologías. Por ejemplo, desde hace unos años existen grupos de la aplicación "WhatsApp" para copleros y copleras. En esos grupos, se coplea a través de audios grabados y textos enviados desde el celular durante todo el año, además de ser un canal de información magnífico sobre esta actividad específica (sobre festivales, reuniones, etc.), que aporta a un proceso identificatorio alrededor de la copla. En estos casos, ¿los copleros y copleras se sustraerán del acto ritual o aparecen otras aristas del fenómeno?

La disidencia con las estructuras sociales tiene un final, luego de algunas horas de explosión sensitiva y la licencia que los participantes de la rueda se otorgaron. Aún varios días después de la experiencia, queda la sensación de escuchar coplas. El oído suena, la vibración percute; las coplas aparecen entre sueńos retumbando, mientras uno vuelve al mundo de las tareas domésticas, a las relaciones interpersonales de lo cotidiano.

\section{Agradecimientos}

Agradezco a Walter Ábalos, Quintino Arias, Mariana Castro, Daniela Cazón, Camila Goyechea, David Quispe, Paulina Quispe y Mariano Mamaní, además de a todas las copleras y copleros con los que compartí momentos de fiesta y canto, pues sin sus experiencias compartidas, este trabajo no sería posible. Asimismo, a Pilar Barrientos y Ana Laura Elbirt por la lectura atenta del borrador. Una versión preliminar de este artículo fue presentada en el Primer encuentro latinoamericano de investigadores sobre cuerpos y corporalidades en las culturas (Facultad de Humanidades y Artes, Universidad Nacional de Rosario, Red de Antropología de y desde los cuerpos, Rosario, Argentina), en agosto de 2012. 


\section{Referencias citadas}

Abercrombie, T. (1992). La fiesta del carnaval postcolonial en Oruro: Clase, etnicidad y nacionalismo en la danza folklórica. Revista Andina, 2, 279-325.

Abercrombie, T. (1993). Caminos de la memoria en un cosmos colonizado. Poética de la bebida y la conciencia histórica en K’ulta. En Saignes, T. (Comp). Borrachera y memoria. La experiencia de lo sagrado en los Andes (pp. 98-120). La Paz: Hisbol - IFEA.

Aretz, I. (1952). El folklore musical argentino. Buenos Aires: Ricordi.

Bajtin, M. (2005). La cultura popular en la Edad Media y en el Renacimiento, el contexto de François Rabelais. Forcat, J. y Conroy, C. (Trads.). Madrid: Alianza.

Bauman, R. (1992). Performance. En Bauman, R. (Ed.). Folklore, Cultural Performances and Popular Entertainments (pp. 41-49). Nueva York-Oxford: Oxford University Press.

Belvedere, C. (2013). Antes de la ciencia. El sentido común en la obra de Alfred Shutz. Astrolabio, 10, $30-44$.

Bertonio, L. (2006 [1612]). Vocabulario de la lengua aymara. Arequipa: Ediciones El Lector.

Bugallo, L. (2010). La estética de la crianza. Los santos protectores del ganado en la puna de Jujuy. En Bovisio, M. A. y Penhos, M. (Coords.). Arte indigena: categorías, prácticas, objetos (pp. 85-102). Buenos Aires: Brujas - Grupo Encuentro.

Bugallo, L. y Vilca, M. (2011) Cuidando el ánimu: salud y enfermedad en el mundo andino (puna y quebrada de Jujuy, Argentina). Nuevo Mundo Mundos Nuevos, 11, 1-17. Recuperado de: http://nuevomundo. revues.org/61781.

Cámara de Landa, E. (1994). La música de la baguala del Noroeste argentino. Tesis doctoral, Universidad de Valladolid, Valladolid, España.

Cámara de Landa, E. (2006). Entre Humahuaca y La Quiaca. Mestizaje e identidad en la música de un carnaval andino. Valladolid: Universidad de Valladolid.

Carrizo, J. A. (1935). Cancionero popular de Jujuy. San Miguel de Tucumán: Universidad Nacional de Tucumán.

Citro, S. (2009). Cuerpos significantes. Travesías de una etnografía dialéctica. Buenos Aires: Editorial Biblos - Culturalia.

Costa, M. y Karasik, G. (1996] 2010). ¿Supay o Diablo? El carnaval en la Quebrada de Humahuaca. En Cruz, E. N. (Ed.). Carnavales fiestas y ferias en el mundo andino de la Argentina (pp.43-74). Salta: Purmamarka Editores.

Cullen, C. (1978). Fenomenología de la crisis moral. Sabiduría de la experiencia de los pueblos. Buenos Aires: Castañeda.

DaMatta, R. (2002). Carnavales, malandros y héroes: hacia una sociología del dilema brasileño, traducido por T. Sule. México: Fondo de Cultura Económica.

Fortuna, C. (2009). "La ciudad de los sonidos. Una heurística de la sensibilidad en los paisajes urbanos contemporáneos", Cuadernos de Antropología Social, 30, 39-58. 
Good, B. (1994). El cuerpo, la experiencia del padecimiento y el mundo de vida: un enfoque fenomenológico del dolor crónico (Cap. 5). En Medicina, Racionalidad y Experiencia. Una Perspectiva Antropológica. Barcelona: Edicions Bellaterra.

Harvey, P. (1993). Género, comunidad y confrontación. Relaciones de poder en la embriaguez en Ocongate, Perú. En Saignes, T. (Comp.). Borrachera y memoria. La experiencia de lo sagrado en los Andes (pp. 79-97). La Paz: Hisbol - IFEA.

Le Breton, A. (1995). Antropología del cuerpo y modernidad. Buenos Aires: Nueva Visión.

López, P. (2020, enero 12). Más de 800 copleros se unieron en el canto popular. El Tribuno. Recuperado de: https:/www.eltribuno.com/jujuy/nota/2020-1-12-1-0-0-mas-de-800-copleros-se-unieron-en-el-cantopopular (Consulta 2.02.2020).

Mennelli, Y. (2007). Un abordaje de la performance de contrapunto de coplas "hombre" y "mujer" en el carnaval humahuaqueño. Tesina de Licenciatura en Antropología, Orientación Etnolingüística. Rosario: Universidad Nacional de Rosario.

Mennelli, Y.(2010a). Carnavales de cuadrillas en Humahuaca: características principales y dilemas actuales. En Cruz, E. N. (Ed.). Carnavales fiestas y ferias en el mundo andino de la Argentina (pp.75-109). Salta: Purmamarka Editores.

Mennelli, Y. (2010b). ¿Con el diablo en el cuerpo? Huellas étnicas y marcas de género del carnaval de cuadrillas humahuaqueño. En Citro, S. (Coord.). Cuerpos plurales. Antropología de y desde los cuerpos. Buenos Aires: Biblos Culturalia.

Merleau-Ponty, M. (1985). Fenomenología de la Percepción. Barcelona: Planeta Agostini.

Mirande, M. E. (2005). Ábrase esta rueda, vuélvase a cerrar. La construcción de la identidad mediante el canto de coplas”. Cuadernos FHYCS, 27, 99-110.

Mirande, M. E. (2010). 'Larguenmé p’al Carnaval...' Borrachera, coplas y contradiscurso femenino en el Carnaval quebradeño. En Cruz, E. N. (Ed.). Carnavales fiestas y ferias en el mundo andino de la Argentina (pp.150-176). Salta: Purmamarka Editores.

Mirande, M. E. (2018). Las que cantan. El copleo femenino en Jujuy: historia y relato. San Salvador de Jujuy: EDIUNJu.

Moreau, B. (2006). Davueltando [documental sobre músicas y fiestas en los valles orientales de altura de Jujuy]. Investigación y guion de W. Ábalos y R. Sánchez Patzy. Buenos Aires: Cosentino - UNESCO - Ministerio de Relaciones Exteriores y Culto. Recuperado de: https://www.youtube.com/watch?v=kb3bjlevMNw

Quignard, P. (2004). Ocurre que las orejas no tienen párpados y otros tratados (C. McLean, Trad.). La Mariposa Mundial, 13/14, Separata.

Randall, R. (1993). Los Dos Vasos. Cosmovisión y política de la embriaguez desde el inkanato hasta la colonia. En Saignes, T. (Comp.). Borrachera y memoria. La experiencia de lo sagrado en los Andes (pp. 49-78). La Paz: Hisbol - IFEA.

Rolandi, D. y Jiménez de Pupareli, D. (1983-1985). El tejido tradicional de La Puna argentino-boliviana. Cuadernos del Instituto Nacional de Antropología y Pensamiento Latinoamericano, 10, 205-289. 
Rosat Pontalti, A. A. (2009). Diccionario Enciclopédico Quechua-Castellano del Mundo Andino (2a edición). Cochabamba: Editorial Verbo Divino.

Saignes, T. (1993). "Estar en otra cabeza": tomar en los Andes. En Saignes, T. (Ed.). Borrachera y memoria. La experiencia de lo sagrado en los Andes (pp. 4-11). La Paz: Hisbol - IFEA.

Saignes, T. (1993). Borracheras andinas: ¿Por qué los indios ebrios hablan en español? En Saignes, T. (Ed.). Borrachera y memoria. La experiencia de lo sagrado en los Andes (pp. 27-48). La Paz: Hisbol -IFEA.

Sánchez Patzy, R. (2006). Música y fiestas en los valles orientales de altura de Jujuy. Buenos Aires: Cosentino - UNESCO - Ministerio de Relaciones Exteriores y Culto.

Sanjinés, J. (1996). Cholos viscerales: desublimación y critica del mestizaje. Cochabamba: CERES - FACES - UMSS.

Schutz, A. [1962] (2008). Sobre las realidades múltiples. En El problema de la realidad social. Escritos I (2a edición) (pp. 197-238). Buenos Aires: Amorrortu.

Stobart, H. (1998). Lo recto y lo torcido: La música andina y la espiral de la descendencia. En Arnold, D. Y. (Comp.). Gente de carne y hueso: Las tramas de parentesco en los Andes (pp. 581-604). La Paz: CIASE ILCA.

Stoeltje, B. y Bauman, R. (1988). The Semiotics of Folkloric Performance. En. Sebeok, T. A. y UmikerSebeok, J. (Eds.). The Semiotic Web (pp. 585-599). Traducción de la cátedra de Folklore General, FFyL, UBA. Berlín-Nueva York-Amsterdam: Mouton de Gruyter.

Taboada, M. S. (1996). La memoria de la copla y las coplas de la memoria. Panorama de la copla en la Argentina. En Atero Burgos, V. (Ed.). El Romancero y la copla: formas de oralidad entre dos mundos (EspañaArgentina) (pp.137-154). Sevilla: Utrera.

Valladares, L. (2000). Cantando las raíces. Coplas ancestrales del Noroeste Argentino. Buenos Aires: Emecé.

Vega, C. (1965). Las canciones folklóricas argentinas. Buenos Aires: Instituto de Musicología y fondo Nacional de las Artes, Ministerio de Educación de la Nación.

Vega, C. (2010 [1944]). Panorama de la música popular argentina con un ensayo sobre la ciencia del Folklore (2a edición). Buenos Aires: Instituto Nacional de Musicología "Carlos Vega".

Vila, P. (1995). "Identidades, narrativa y música. Una primera propuesta teórica para entender sus relaciones”. En II Encuentro del Grupo Iberoamericano de Etnomusicología, Barcelona, España.

Zapana, M. (2011). El contrapunto coplero de la Quebrada y Puna jujeñas. San Salvador de Jujuy: EdiUNJu y Secretaría de Turismo y Cultura de Jujuy. 